An aggressive attitude towards another individual, once begun, seems to remain fixed, and will lead to a fatal feud unless the animals are separated. Fighting occurs just as frequently in the large as in the small cages.

Copulation, first observed in January of this year, occurred with increasing frequency during February and March and declined through April and May. Nineteen out of twenty-four females were observed to copulate at least once; eight became palpably pregnant, some individuals more than once, with thirteen pregnancies in all. All but one of the pregnant females either aborted or killed and ate their young the night they were born. The exception ( $T f 39)$ has given birth twice; the first pair of young was neglected and was found dead and trampled in the nest box litter four days after birth; the second pair was eaten by the mother on the third day. Tf39 became pregnant a third time but aborted or resorbed the embryos at about half term.

There is no indication of male sterility, all males appearing sexually vigorous. The females appear to suffer from some factor or factors antipathetic to reproduction manifested by refusal to mate, sterility, spontaneous abortion, litter killing, and neglect of the young. In no case has there been any record of enlargement of mammary glands in pregnant females ; the single case of neglect of the young may have been due to milk failure.

The gestation period for Tupaia glis, as indicated by the records to date, is between 46 and 50 days. Of six pregnancies for which the number of embryos is certain, there were twins in five cases and a single young in the sixth. (These records include autopsies on three pregnant newly captured females which were received dead.)

Female Tf39 showed what I interpret as post partum heat; she achieved a fertile mating between 48 and $72 \mathrm{hr}$. after parturition.

Observations to date indicate that male sexual aggressiveness is stimulated by female secretions and that the female goes through a socio-psychological pattern similar to that of heat in non-primates.

Cases of intra-uterine bleeding suggestive of menstruation are being investigated at present.

Acknowledgment is due to the Institute for Medical Research, Kuala Lumpur, Malaya, and to the U.S. Army Medical Research Unit in South-East Asia for supply of Malayan specimens and for financial aid in obtaining animals from Thailand respectively. Both bodies are interested in breeding of tree shrews as laboratory hosts of primate virus diseases. The study is proceeding, and I would welcome communication from interested workers.

Note added in proof, Sept. 29. A litter of two born on August 20 is now being weaned.

$$
\begin{gathered}
\text { Zoology Department, } \\
\text { University of Malaya, } \\
\text { Singapore. } \\
\text { June } 21 .
\end{gathered}
$$

\section{Attempts at Nitrogen Fixation in vitro}

The low activation energies generally associated with free-radical reactions have prompted several workers to explain the high velocity of various biological processes ${ }^{1,2}$, including nitrogen fixa.tion ${ }^{3,4}$, by mechanisms involving free radicals. Burris's fixation mechanism ${ }^{3}$ postulated an enzyme-hydrogen peroxide complex and reduction or oxidation of molecular nitrogen by the free radical $A_{h} . \mathrm{H} \cdot$ or $A_{0} .(\mathrm{OH})^{\cdot}$, respectively, in the latter case producing $\mathrm{N}_{2}(\mathrm{OH})_{2}$. Pethica et al. ${ }^{4}$ suggested that nitrogenase, like catalase ${ }^{5}$ and methæmoglobin ${ }^{6}$, functions by way of a ferrous-ferric couple activated (as in Fenton's reagent) by hydrogen peroxide, which they regarded as an intermediate in respiration. The link between respiration and fixation could be hydroxyl radicals which reacted with nitrogen to form $\mathrm{N}_{2}(\mathrm{OH})_{2}$.

Attempts were made, using the isotopic technique, to detect in vitro fixation by cell-free extracts from Azotobacter vinelandii in the presence of free hydrogen and hydroxyl radicals. Extracts from vigorous cultures were prepared by grinding centrifuged and washed cells with powdered 'Pyrex' glass and phosphate buffer solution $(p \mathrm{H} 7 \cdot 0)$ at $-2^{\circ} \mathrm{C}$.; the paste was spun out and the supernatant used immediately. An atmosphere of oxygen and heavy nitrogen was circulated by means of the apparatus previously described ${ }^{3,8}$ through various solutions in the culture flasks for five hours. In case oxygen gas, some constituent of the medium ${ }^{3}$, or free radicals were necessary before nitrogenase could function, these were supplied, singly and together. Hydrogen and hydroxyl radicals, which would according to Pethica be supplied in vivo by the respiratory system, were generated in vitro by reaction between $M$ ferrous sulphate and $M / 2$ hydrogen peroxide (inhibitor-free), one drop of each being added every five seconds throughout the experiment.

No shift in the abundance ratios of the atmosphere was observed in any experiment, nor were any gas samples obtained from the various solutions by the Kjeldahl digestion process ${ }^{3}$. In five hours, the equivalent of eighty litres of labelled atmosphere, containing 26.0 atom per cent excess nitrogen-15, passed through each solution, so that it is clear that no fixation of nitrogen is possible under the conditions described. It may be that nitrogenase does not survive the extraction, or must be augmented in some way not at present understood. It is of interest that nitrogen can be fixed in aqueous solution by an electric discharge. Campardou ${ }^{9}$ gives the equations :

$$
\begin{aligned}
\mathrm{N}_{2}+2 \mathrm{H}_{2} \mathrm{O} & \rightarrow \mathrm{NH}_{4} \mathrm{NO}_{2} \\
\mathrm{NH}_{4} \mathrm{NO}_{2}+\frac{1}{2} \mathrm{O}_{2} & \rightarrow \mathrm{NH}_{4} \mathrm{NO}_{3}
\end{aligned}
$$

and observes that the net reaction uses nitrogen and oxygen in the exact proportion in which they dissolve in water at one atmosphere pressure. However, the results above, together with failure 8,10 to demonstrate the importance of compounds of formula $\mathrm{N}_{2}(\mathrm{OH})_{2}$ (which is common to the different free radical postulates), constitute strong experimental evidence against such postulates.

Department of Inorganic and

T. G. G. WILSON

E. R. Roberts Physical Chemistry,

Imperial College of Science and Technology, London, S.W.7. July 2.

\footnotetext{
${ }^{1}$ Hinshelwood, C. N., "Chemical Kinetics of the Bacterial Cell" (Oxford Univ. Press, 1946).

${ }^{2}$ Weiss, J., J. Phys. Chem., 41, 1107 (1937).

' Wilson, P. W., and Burris, R. H., Bact. Rev., 11. 41 (1947).

- Pethica, B. A., Roberts, F. R., and Winter, E. R. S., Biochim. Biophys. Acta, 14, 85 (1954).

- George, P., Nature, 160, 41 (1947).

${ }^{6}$ Keilin, D., and Hartree, E. F., Nature, 166, 514 (1950).

'Mers, J. H., and Waters, W. A., Farad. Soc. Discus3., 42, 179 (1947). ${ }^{8}$ Wilson, T. G. G., and Roberts, E. R., Biochim. Biophys. Acta (in the press).

- Campardou, J., Bull. Soc. Chim., 789 (1947).

${ }^{10}$ Chaudhary, M. T., Wilson, T. G. G., and Roberts, E. R., Biochim. Biophys. Acta, [14, 507 (1954)].
} 